\title{
Xanthine oxidase inhibition reduces reactive nitrogen species production in COPD airways
}

\author{
M. Ichinose*, H. Sugiura\#, S. Yamagata\# , A. Koarai\#, M. Tomaki\#, H. Ogawa ${ }^{\#}$, Y. Komaki\#, P.J. Barnes", \\ K. Shirato ${ }^{\#}$, T. Hattori ${ }^{\#}$
}

Xanthine oxidase inhibition reduces reactive nitrogen species production in COPD airways. M. Ichinose, H. Sugiura, S. Yamagata, A. Koarai, M. Tomaki, H. Ogawa, Y. Komaki, P.J. Barnes, K. Shirato, T. Hattori. (C) ERS Journals Ltd 2003.

ABSTRACT: Reactive nitrogen species (RNS) have been reported to be involved in the inflammatory process in chronic obstructive pulmonary disease (COPD). However, there are no studies on the modulation of RNS in COPD. It was hypothesised that inhibition of xanthine oxidase (XO) might decrease RNS production in COPD airways through the suppression of superoxide anion production.

Ten COPD and six healthy subjects participated in the study. The XO inhibitor allopurinol (300 mg. day $^{-1}$ p.o. for 4 weeks) was administered to COPD patients. RNS production in the airway was assessed by 3 -nitrotyrosine immunoreactivity and enzymic activity of $\mathrm{XO}$ in induced sputum as well as by exhaled nitric oxide (eNO) concentration.

XO activity in the airway was significantly elevated in COPD compared with healthy subjects. Allopurinol administration to COPD subjects significantly decreased XO activity and nitrotyrosine formation. In contrast, eNO concentration was significantly increased by allopurinol administration.

These results suggest that oral administration of the xanthine oxidase inhibitor allopurinol reduces airway reactive nitrogen species production in chronic obstructive pulmonary disease subjects. This intervention may be useful in the future management of chronic obstructive pulmonary disease.

Eur Respir J 2003; 22: 457-461.
*Third Dept of Internal Medicine, Wakayama Medical University, Wakayama, " Division of Respiratory and Infectious Diseases, Tohoku University Graduate School of Medicine, Sendai, Japan. 'Dept of Thoracic Medicine, National Heart and Lung Institute, Imperial College, London, UK.

Correspondence: M. Ichinose, Third Dept of Internal Medicine, Wakayama Medical University, Wakayama 811-1, Japan.

Fax: 81734462877

E-mail:masakazu@wakayama-med.ac.jp

Keywords: Chronic obstructive pulmonary disease, exhaled nitric oxide, nitrotyrosine

Received: June 192002

Accepted after revision: April 132003

This study was supported by Science Research Grants 12470132 and 14657143 from the Ministry of Education, Culture, Sports, Science and Technology, Tokyo, Japan.
Chronic obstructive pulmonary disease (COPD) is a major medical problem and there is evidence that it is increasing throughout the world [1-3]. The inflammatory process has been reported to play an important role in the perpetuation of the disease, although the precise inflammatory mechanisms of COPD are not well understood [4].

Cigarette smoke is a major trigger of the inflammation observed in COPD, although exsmokers show similar airway inflammation to that of current smokers [5]. Therefore, endogenous mechanisms seem to be involved in the pathogenesis of the inflammatory process in COPD. Oxidative stress may be one of the mechanisms that amplifies and perpetuates the inflammatory process in COPD [4, 6-8]. The high level of production of nitric oxide (NO) during inflammatory/immune processes of the respiratory tract is thought to constitute a host defence mechanism, although it may also cause respiratory tract injury and contribute to the pathophysiology of COPD [9]. The adverse effects of $\mathrm{NO}$ are thought to be engendered, in part, by its reaction with superoxide anions, which are released from infiltrating inflammatory cells, such as macrophages and neutrophils, yielding potent reactive nitrogen species (RNS), such as peroxynitrite, which results in the nitration of tyrosine residues in proteins [10-12]. Recently, increased production of RNS, assessed via increased numbers of cells in induced sputum which were immunoreactive for 3-nitrotyrosine, was reported [13]. There was correlation between this measurement

For editorial comments see page 401. and the severity of COPD, indicating that RNS may be important in the inflammatory mechanisms of COPD.

In the present report, allopurinol, an inhibitor of xanthine oxidase (XO), an enzyme responsible for superoxide anion production, was administered and changes in nitrotyrosine formation in COPD subjects evaluated.

\section{Methods}

\section{Subjects}

Ten patients (nine male) with COPD took part in the study after giving informed consent. The study was approved by the local ethics committee and subjects were aged 52-76 yrs. Their mean \pm SEM forced expiratory volume in one second (FEV1) was $1.40 \pm 0.2 \mathrm{~L}$ or $46.3 \pm 4.9 \%$ of the predicted value. All patients satisfied American Thoracic Society criteria for COPD and had stopped smoking $\geqslant 1 \mathrm{yr}$ before the study. All were stable and had not been treated with steroids for $\geqslant 6$ months. All bronchodilator therapy was stopped $\geqslant 24 \mathrm{~h}$ before measurements were made.

\section{Study protocol}

Nitrotyrosine immunoreactivity, XO activity and differential cell counts in induced sputum were measured before and 
during XO inhibitor (allopurinol, $300 \mathrm{mg} \cdot \mathrm{day}^{-1}$ in three doses p.o. for 4 weeks) administration. Exhaled NO (eNO) levels and FEV1 were also examined at that time using a chemiluminescence analyser (280NOA; Sievers, Boulder, CO, USA) and dry rolling-seal spirometer (OST 80A; Chest Co., Tokyo, Japan), respectively. Four weeks after discontinuing allopurinol, the above procedures were repeated.

\section{Measurement of nitric oxide concentration}

eNO was measured as previously described [14]. Subjects exhaled from total lung capacity at a constant flow of $2.5 \mathrm{~L} \cdot \mathrm{min}^{-1}$. The pressure of the oral cavity was maintained at $1.96 \mathrm{kPa}$ to close the velum, thus excluding nasally derived NO contamination. The exhaled air was absorbed at a sample flow of $250 \mathrm{~mL} \cdot \mathrm{min}^{-1}$ via a side port close to the mouth. At least two successive recordings at 2-min intervals were made and the mean of the peak values from two reproducible readings was used in the analysis of results. eNO was measured before spirometry was performed.

\section{Sputum induction and examination}

Fifteen minutes after pretreatment with fenoterol $(400 \mu \mathrm{g}$, by inhalation), hypertonic saline $(4 \%)$ inhalation was performed using an ultrasonic nebuliser (MU-32; Sharp Co. Ltd, Osaka, Japan; mean mass median aerodynamic diameter and output were $5.4 \mu \mathrm{m}$ and $2.2 \mathrm{~mL} \cdot \mathrm{min}^{-1}$, respectively). Samples that contained saliva (squamous epithelial cells) were eliminated by visual inspection and inverted microscope examination $[15,16]$. Hypertonic saline inhalation was continued for 15-30 min until the sputum volume was $\sim 1 \mathrm{~mL}$.

The sputum sample was immediately treated with Sputasol (Oxoid Ltd, Basingstoke, UK) in a volume four times that of the original sample to dissociate the disulphide bonds of the mucus. The mixture was agitated on a vortex mixer for $15 \mathrm{~s}$ and gently aspirated in and out of a Pasteur pipette to ensure mixing. The sample was shaken for $15 \mathrm{~min}$ and phosphatebuffered saline (PBS; pH 7.4) added to terminate the effect of Sputasol. After centrifugation of the sample for $10 \mathrm{~min}$ at $790 \times g$, the cell pellet was resuspended with $50 \mathrm{mM}$ PBS (the volume of PBS was half of original sputum volume) and the total leukocyte count obtained using a haemocytometer. Cell viability was determined by trypan blue exclusion. The total and absolute cell densities (per millilitre of processed sputum) were calculated. Cell suspension $(100 \mu \mathrm{L})$ adjusted to $1.0 \times 10^{6}$ cells $\cdot \mathrm{mL}^{-1}$ was placed into the cups of a Shandon III cytocentrifuge (Shandon Southern Instruments, Sewickley, PA, USA) to give four preparations per sample [15]. The samples were stained using Hansel's stain (Torii Pharmaceutical, Tokyo, Japan) to assess the cell differential count [17] and stored at $-80^{\circ} \mathrm{C}$ until immunocytochemical analysis.

\section{Immunocytostaining}

Samples were immunostained using antiserum directed against 3-nitrotyrosine. Briefly, each sample was fixed in 4\% paraformaldehyde fixative solution for $30 \mathrm{~min}$. Endogenous peroxidase activity was reduced by incubation in 3\% hydrogen peroxide in $100 \%$ methanol for $5 \mathrm{~min}$ at room temperature. After washing in PBS, the preparation was incubated with the primary antibody (polyclonal rabbit antinitrotyrosine immunoglobulin (Ig)G, 1:100 dilution; Upstate biotechnology, Lake Placid, NY, USA) [13, 18] for $12 \mathrm{~h}$ at $4{ }^{\circ} \mathrm{C}$. In order to reduce nonspecific ionic binding of the antibody, the preparations were preincubated with $4 \%$ nonfat milk in PBS containing $0.3 \%$ Triton X (Sigma, St Louis, MO USA) for $30 \mathrm{~min}$ and then incubated with $10 \%$ inactivated normal goat serum for $30 \mathrm{~min}$ at room temperature. When the antibody directed against nitrotyrosine was incubated with excess nitrotyrosine, immunoreactivity was blocked, indicating high specificity of the antibody for nitrotyrosine. Immunoreactivity was visualised using the indirect immunoperoxidase method and EnVision polymer reagent (DAKO Japan Ltd, Kyoto, Japan), goat antirabbit IgG conjugated with peroxidase-labelled dextran, for $1 \mathrm{~h}$ at room temperature. The diaminobenzidine reaction was then performed, where tissues were incubated with a solution of $200 \mathrm{~mL}$ of PBS, $10 \mathrm{mg}$ of diaminobenzidine, $72.5 \mathrm{mg}$ of sodium azide and $112 \mu \mathrm{L} \mathrm{H}_{2} \mathrm{O}_{2}(30 \%)$. This was followed by counterstaining with Hansel's stain. Differential and immunoreactive cell counts were made by two qualified cytopathologists, blind to the origin of the samples, who counted 500 cells in each sample. The mean of both scores was used for analysis.

\section{Xanthine oxidase activity measurement}

XO activity was measured using the method of AKAIKE et al. [19]. Briefly, supernatants of the processed sputum samples were prepared as mentioned previously. Immediately afterwards, an inhibitor cocktail (ice-cold $50 \mathrm{mM}$ potassium phosphate buffer containing $2 \mathrm{mM}$ ethylenediamine tetraacetic acid (EDTA), $2 \mathrm{mM}$-amidinophenylmethanesulphonyl fluoride, $10 \mathrm{mM}$ dithiothreitol and $0.5 \mu \mathrm{g} \cdot \mathrm{mL}^{-1}$ leupeptin) was added. Next, samples were centrifuged for $10 \mathrm{~min}$ at $790 \times g$ and the supernatants recentrifuged for $1 \mathrm{~h}$ at $100,000 \times g$ at $4{ }^{\circ} \mathrm{C}$. The supernatants were filtered through a $0.45-\mu \mathrm{m}$ Millipore filter (Millipore, Billerica, MA, USA). In order to remove low molecular weight compounds (e.g. xanthine and hypoxanthine), they were then dialysed for $5 \mathrm{~h}$ against $10 \mathrm{~L}$ PBS at $4^{\circ} \mathrm{C}$ in cellulose tubing (Seamless Cellulose Tubing size 8/32; Sankou Pure Chemical Industries, Tokyo, Japan) before determination of XO activity. All samples were assayed for $\mathrm{XO}$ activity using pterin as substrate in a spectrofluorometer (model 650-40; Hitachi Ltd, Tokyo, Japan) with excitation at $345 \mathrm{~nm}$ and emission at $390 \mathrm{~nm}$. The volume of the assay mixture was $1.0 \mathrm{~mL}$ in PBS, containing $9 \mu \mathrm{M}$ pterin and $50 \mu \mathrm{L}$ sample solution. Reactions were allowed to proceed for $1 \mathrm{~h}$ at $37^{\circ} \mathrm{C}$. In order to measure $\mathrm{XO}$ activity, the above reactions were carried out in the presence of $9 \mu \mathrm{M}$ methylene blue. To confirm the specificity of the activity, $20 \mu \mathrm{M}$ allopurinol was added to the sample. Activity was determined by means of isoxanthopterin formation and expressed as nanomoles of isoxanthopterin formed per millilitre per hour.

\section{Statistical analysis}

Data are presented as mean \pm SEM or as median (range), when appropriate. Comparisons of median data were performed using a Wilcoxon signed-rank test and of mean data using an unpaired t-test. Changes were considered significant at $\mathrm{p}<0.05$.

\section{Results}

As shown in table 1, allopurinol administration had no significant effect on total cell counts in the induced sputum. However, numbers of nitrotyrosine-immunopositive total cells $(\mathrm{p}<0.01)$, neutrophils $(\mathrm{p}<0.01)$ and macrophages $(\mathrm{p}<0.05)$ were significantly reduced by allopurinol (table 2 ). 
Table 1.-Differential cell counts in induced sputum before, during and after (washout) allopurinol administration

\begin{tabular}{lccccc}
\hline & $\begin{array}{c}\text { Total cells } \\
10^{4} \text { cells } \cdot \mathrm{mL}^{-1}\end{array}$ & $\begin{array}{c}\text { Macrophages } \\
10^{4} \text { cells } \cdot \mathrm{mL}^{-1}\end{array}$ & $\begin{array}{c}\text { Neutrophils } \\
10^{4} \text { cells } \cdot \mathrm{mL}^{-1}\end{array}$ & $\begin{array}{c}\text { Eosinophils } \\
10^{4} \text { cells } \cdot \mathrm{mL}^{-1}\end{array}$ & $\begin{array}{c}\text { Lymphocytes } \\
10^{4} \text { cells } \cdot \mathrm{mL}^{-1}\end{array}$ \\
\hline Before & $120.0(51.0-684.0)$ & $34.5(16.0-204.0)$ & $114.0(10.2-512.0)$ & $7.0(0.0-40.9)$ & $6.3(1.7-15.7)$ \\
During & $121.0(64.0-508.0)$ & $46.9(8.7-134.0)$ & $91.3(16.8-385.0)$ & $6.2(1.4-27.4)$ & $5.8(3.5-17.7)$ \\
Washout & $224.0(95.0-516.0)$ & $168(67.0-378.0)$ & $36.0(20.0-134.0)$ & $9.0(3.0-20.0)$ & $5.0(11.0-30.0)$ \\
\hline
\end{tabular}

Data are presented as median (range).

Table 2.-3-nitrotyrosine-immunopositive cell counts in induced sputum before, during and after (washout) allopurinol administration

\begin{tabular}{lccccc}
\hline & $\begin{array}{c}\text { Total cells } \\
10^{4} \text { cells } \cdot \mathrm{mL}^{-1}\end{array}$ & $\begin{array}{c}\text { Macrophages } \\
10^{4} \text { cells } \cdot \mathrm{mL}^{-1}\end{array}$ & $\begin{array}{c}\text { Neutrophils } \\
10^{4} \text { cells } \cdot \mathrm{mL}^{-1}\end{array}$ & $\begin{array}{c}\text { Eosinophils } \\
10^{4} \mathrm{cells} \cdot \mathrm{mL}^{-1}\end{array}$ & $\begin{array}{c}\text { Lymphocytes } \\
10^{4} \mathrm{cells} \cdot \mathrm{mL}^{-1}\end{array}$ \\
\hline Before & $63.9(23.3-485.0)$ & $15.9(12.0-86.6)$ & $44.3(5.5-396.4)$ & $0.0(0.0-12.7)$ & $0.0(0.0-0.0)$ \\
During & $40.7(7.3-67.2)^{* *}$ & $7.5(1.4-40.2)^{*}$ & $18.0(2.9-47.3)^{* *}$ & $0.0(0.0-0.9)$ & $0.0(0.0-0.0)$ \\
Washout & $85.5(37.0-375.0)$ & $23.0(5.0-70.0)$ & $63.0(30.1-302.0)$ & $1.0(0.0-7.0)$ & $0.0(0.0-0.0)$ \\
\hline
\end{tabular}

Data are presented as median (range). ${ }^{*}: \mathrm{p}<0.05$ versus before and washout; ${ }^{* *}$ : $<<0.01$ versus before and washout.

At baseline, median airway XO activity was $150.0(58.3-$ 515.0) $\mathrm{nmol} \cdot \mathrm{mL}^{-1} \cdot \mathrm{h}^{-1}$ isoxanthopterin, significantly greater than that of age-matched healthy subjects (45.4 (20.8-71.9) $\mathrm{nmol} \cdot \mathrm{mL}^{-1} \cdot \mathrm{h}^{-1}$ isoxanthopterin; $\mathrm{n}=6, \mathrm{p}<0.01$ ) (data not shown). The activity in COPD subjects was significantly reduced by allopurinol administration to a median of 89.7 (29.0-227.0) $\mathrm{nmol} \cdot \mathrm{mL}^{-1} \cdot \mathrm{h}^{-1}$ isoxanthopterin $(\mathrm{p}<0.01)$ (fig. 1a).

Nitrotyrosine-immunopositive cell counts were also significantly decreased from a median of $35.1 \%$ (range 20.8-70.9) to a median of $15.6 \%(8.2-47.8)$ during allopurinol administration $(\mathrm{p}<0.01)$ (fig. 1b).

In contrast, eNO levels were significantly elevated from a median of 11.2 parts per billion (ppb) (5.0-26.2) to a median of $16.8 \mathrm{ppb}(10.8-36.0)$ by allopurinol administration $(\mathrm{p}<0.01)$ (fig. 1c). The allopurinol-induced changes in XO activity, nitrotyrosine-immunopositive cell counts and eNO concentration returned to baseline values after the allopurinol had been discontinued for 4 weeks (fig. 1).

Allopurinol treatment caused no change in FEV1. The FEV1 before and after allopurinol administration and after its discontinuation were $1.42 \pm 0.16,1.50 \pm 0.19$ and $1.44 \pm 0.17 \mathrm{~L}$, respectively.

\section{Discussion}

In the present report, it has been shown that administration of the XO inhibitor allopurinol can suppress airway production of 3-nitrotyrosine, a footprint of peroxynitrite and other RNS, and inhibit the increased XO activity in COPD subjects.

The formation of nitrotyrosine depends on oxidation of NO [20]. NO reacts with the superoxide anion to yield the powerful oxidant peroxynitrite, which is presumed to be largely responsible for the adverse effects of excessive NO generation [21]. Recently, it was reported that RNS production as assessed by induced sputum 3-nitrotyrosine immunostaining was significantly elevated in COPD subjects [13]. Further, there was a significant correlation between the degree of airway obstructive changes and the amount of nitrotyrosine formation in COPD.

Peroxynitrite adds nitrates to position 3 , adjacent to the hydroxyl group, of tyrosine to produce the stable product
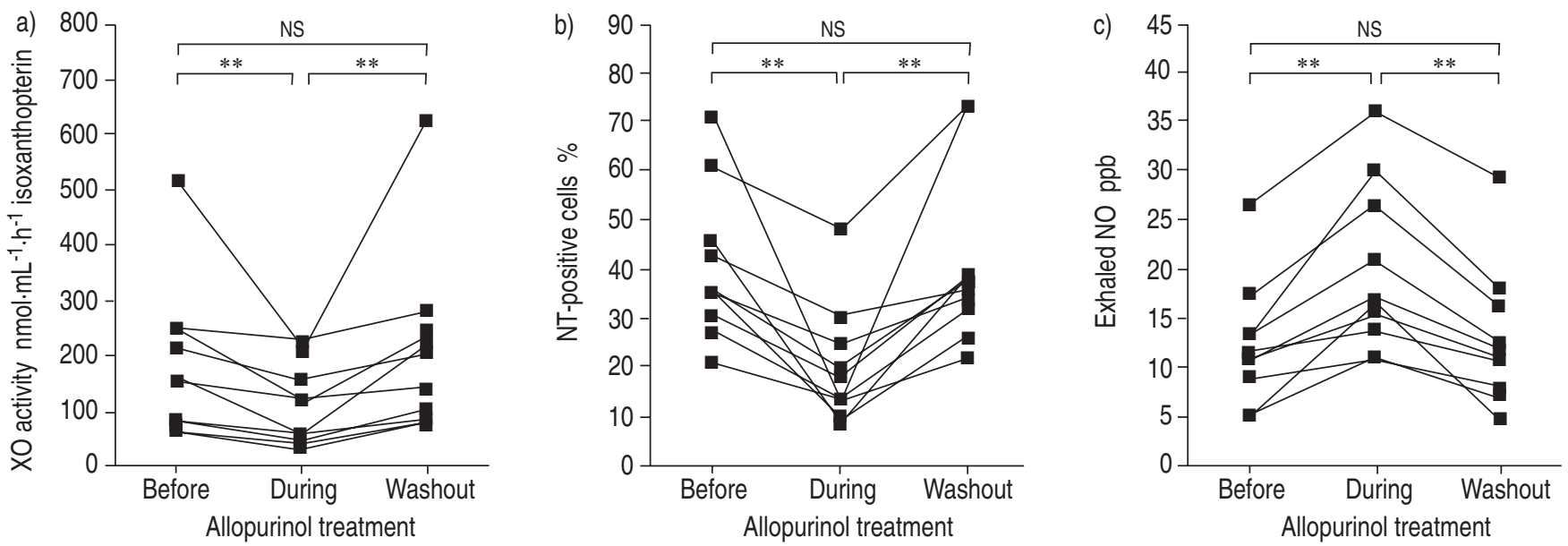

Fig. 1.-Effect of allopurinol treatment on a) xanthine oxidase (XO) activity, b) 3-nitrotyrosine (NT)-immunopositive cell counts in induced sputum, and c) exhaled nitric oxide (eNO) levels before, during and after (washout) administration. ppb: parts per billion; NS: nonsignificant. $* *: p<0.01$. 
3-nitrotyrosine [22, 23], and has highly pro-inflammatory actions via oxidative stress and lipid peroxidation $[10,11]$. Peroxynitrite also activates matrix metalloproteinases released from neutrophils and macrophages, which are capable of degrading all of the components of the extracellular matrix of the lung parenchyma [24] and may cause emphysematous changes. Therefore, modulation of peroxynitrite formation should be useful in suppressing the inflammatory and destructive process observed in COPD.

Since $\mathrm{XO}$ is able to generate superoxide anions, the allopurinol-induced reduction of nitrotyrosine observed in the present study appears to have been due to inhibition of peroxynitrite formation via suppression of superoxide production. In the present study, baseline XO activity in induced sputum was four times higher in COPD patients than in healthy subjects. XO activity in the airways has been reported using bronchoalveolar lavage fluid analysis via a deoxyribonucleic acid unwinding method [7] and electron paramagnetic resonance and high-performance liquid chromatography [25]. In these reports, XO activity was elevated in COPD patients compared to healthy subjects. These previous reports are compatible with the present study.

In a recent study, it was shown that almost identical amounts of airway inflammatory cell inducible NO synthase immunoreactivity are observed in bronchial asthma and COPD subjects [13]. However, the eNO concentration was significantly higher in bronchial asthma compared to COPD. Therefore, it was hypothesised that NO produced in COPD airways is consumed by its reaction with the superoxide anion [13]. In the present study, XO inhibitor administration significantly increased the eNO concentration in parallel with a decrease in 3-nitrotyrosine formation in COPD subjects, supporting this hypothesis.

An alternative pathway of nitrotyrosine formation via $\mathrm{NO}$ involves mechanisms dependent on myeloperoxidase (MPO) or related peroxidases $[20,26]$. NO reacts with oxygen to form nitrite. Oxidation of nitrite by MPO or other related peroxidases results in the formation of nitryl chloride and nitrogen dioxide. These reactive nitrogen intermediates are also involved in the nitration of tyrosine. Since neutrophilderived MPO is abundant in COPD airways [27], nitrotyrosine formation via these pathways may also have an important role in nitrotyrosine formation in COPD. Since XO inhibition has no effect on these pathways, nitrotyrosine production may have been incompletely suppressed in the present study.

In the present study, inflammatory cell numbers in induced sputum were not significantly influenced by allopurinol administration. This evidence suggests that endogenous superoxide is not involved in the mechanisms of adhesion and chemoattraction of inflammatory cells in COPD airways. Again, allopurinol treatment had no significant effect on airway caliber as assessed by FEV1. This would suggest that endogenously produced superoxide does not exhibit acute bronchoconstrictive action. However, as mentioned earlier, superoxide could be involved in the inflammatory process in COPD airways via reaction with NO. Persistent inflammation in the airway and parenchyma causes progressive airway obstructive change in COPD $[2,4,28]$. Therefore, it is possible that inhibition of superoxide production via endogenous XO suppression can slow the progression of airway obstruction in COPD patients.

In summary, it has been shown that administration of the xanthine oxidase inhibitor allopurinol suppresses xanthine oxidase activity and reduces formation of reactive nitrogen species in the airways of chronic obstructive pulmonary disease patients. Although it has been reported that allopurinol administration suppresses exercise-induced oxidative stress in chronic obstructive pulmonary disease subjects, presumably acting at the skeletal muscle level [28], the present report is the first describing an inhibitory activity of allopurinol on airway reactive nitrogen species production. At present, no drug therapy is able to suppress the inflammatory process observed in chronic obstructive pulmonary disease airways. Reactive nitrogen species cause airway inflammation via oxidative stress and lipid peroxidation, as well as through activation of proteolytic enzymes [29]. The reduction in reactive nitrogen species formation by endogenous xanthine oxidase inhibition may be useful in reducing the inflammatory and destructive process in chronic obstructive pulmonary disease. Further long-term studies are needed to confirm this hypothesis.

\footnotetext{
Acknowledgement. The authors thank B. Bell for reading the manuscript.
}

\section{References}

1. Murray CJL, Lopez AD. Evidence-based health policy: lessons from the global burden of disease study. Science 1996; 274: 740-743.

2. American Thoracic Society. Standards for the diagnosis and care of patients with chronic obstructive pulmonary diseases (COPD) and asthma. Am Rev Respir Dis 1987; 136: 225-244.

3. Pauwels RA, Buist AS, Calverley PMA, Jenkins CR, Hurd SS. Global strategy for the diagnosis, management, and prevention of chronic obstructive pulmonary disease. $\mathrm{Am} \mathrm{J}$ Respir Crit Care Med 2001; 163: 1256-1276.

4. Barnes PJ. New therapy for chronic obstructive pulmonary disease. Thorax 1998; 53: 137-147.

5. Turato G, Di Stefano A, Maestrelli P, et al. Effect of smoking cessation on airway inflammation in chronic bronchitis. Am J Respir Crit Care Med 1995; 152: 1262-1267.

6. Rahman I, Morrison D, Donaldson K, MacNee W. Systemic oxidative stress in asthma, COPD, and smokers. Am J Respir Crit Care Med 1996; 154: 1055-1060.

7. Pinamonti S, Muzzoli M, Chicca MC, et al. Xanthine oxidase activity in bronchoalveolar lavage fluid from patients with chronic obstructive pulmonary disease. Free Radic Biol Med 1996; 21: 147-155.

8. Repine JE, Bast A, Lankhorst I. Oxidative stress in chronic obstructive pulmonary disease. Am J Respir Crit Care Med 1997; 156: 341-357.

9. Kharitonov SA, Yates D, Robbins RA, Logan-Sinclair R, Shinebourne EA, Barnes PJ. Increased nitric oxide in exhaled air of asthmatic patients. Lancet 1994; 343: 133-135.

10. Beckman JS, Beckman TM, Chen J, Marshall PA, Freeman BA. Apparent hydroxyl radical production by peroxynitrite: implication for endothelial injury from nitric oxide and superoxide. Proc Natl Acad Sci USA 1990; 87: 1620-1624.

11. Beckman JS. Oxidative damage and tyrosine nitration from peroxynitrite. Chem Res Toxicol 1996; 9: 836-844.

12. Sugiura $\mathrm{H}$, Ichinose $\mathrm{M}$, Oyake $\mathrm{T}$, et al. Role of peroxynitrite in airway microvascular hyperpermeability during late allergic phase in guinea pigs. Am J Respir Crit Care Med 1999; 160: 663-671.

13. Ichinose M, Sugiura H, Yamagata S, Koarai A, Shirato K Increased reactive nitrogen species production in chronic obstructive pulmonary disease airways. Am J Respir Crit Care Med 2000; 162: 701-706.

14. Silkoff PE, McClean PA, Slutsky AS, et al. Marked flowdependence of exhaled nitric oxide using a new technique to exclude nasal nitric oxide. Am J Respir Crit Care Med 1997; 155: 260-267

15. Tomaki M, Ichinose M, Miura M, et al. Elevated substance $\mathrm{P}$ content in induced sputum from patients with asthma and patients with chronic bronchitis. Am J Respir Crit Care Med 1995; 151: 613-617.

16. Pizzichini E, Pizzichini MMM, Efthimiadis A, et al. Indices 
of airway inflammation in induced sputum: reproducibility and validity of cell and fluid-phase measurements. $A m J$ Respir Crit Care Med 1996; 154: 308-317.

17. Kay AB, Austen KF. The IgE-mediated release of an eosinophil leukocyte chemotactic factor from human lung. J Immunol 1971; 107: 899-902.

18. Saleh D, Ernst P, Lim S, Barnes PJ, Giaid A. Increased formation of the potent oxidant peroxynitrite in the airways of asthmatic patients is associated with induction of nitric oxide synthase: effect of inhaled glucocorticoid. FASEB $J$ 1998; 12: 929-937.

19. Akaike $\mathrm{T}$, Ando $\mathrm{M}$, Oda $\mathrm{T}$, et al. Dependence on $\mathrm{O}_{2}^{-}$generation by xanthine oxidase of pathogenesis of influenza virus infection in mice. J Clin Invest 1990; 85: 739-745.

20. van der Vliet A, Eiserich JP, Shigenaga MK, Cross CE. Reactive nitrogen species and tyrosine nitration in the respiratory tract. Am J Respir Crit Care Med 1999; 160: 1-9.

21. Beckman JS, Koppenol WH. Nitric oxide, superoxide, and peroxynitrite. Am J Physiol 1996; 271: C1424-C1437.

22. Ischiropoulos $\mathrm{H}$, Zhu $\mathrm{L}$, Chen $\mathrm{J}$, et al. Peroxynitritemediated tyrosine nitration catalyzed by superoxide disumutase. Arch Biochem Biophys 1992; 298: 431-437.

23. Beckman JS, Ischiropoulos $\mathrm{H}$, Zhu L, et al. Kinetics of superoxide disumutase- and iron-catalyzed nitration of phenolics by peroxynitrite. Arch Biochem Biophys 1992; 298: 438-445.

24. Okamoto T, Akaike T, Nagano T, et al. Activation of human neutrophil procollagenase by nitrogen dioxide and peroxynitrite: a novel mechanism for procollagenase activation involving nitric oxide. Arch Biochem Biophys 1997; 342: 261-274.

25. Pinamonti S, Leis M, Barbieri A, et al. Detection of xanthine oxidase activity products by EPR and HPLC in bronchoalveolar lavage fluid from patients with chronic obstructive pulmonary disease. Free Radic Biol Med 1988; 25: 771-779.

26. Eiserich JP, Hristova M, Cross CE, et al. Formation of nitric oxide-derived inflammatory oxidants by myeloperoxidase in neutrophils. Nature 1998; 391: 393-397.

27. Keatings VM, Jatakanon A, Worsdell YM, Barnes PJ. Effects of inhaled and oral glucocorticoids on inflammatory indices in asthma and COPD. Am J Respir Crit Care Med 1997; 155: 542-548.

28. Heunks LMA, Vina J, van Herwaaden CLA, Folgering HTM, Gimeno A, Dekhuijzen PNR. Xanthine oxidase is involved in exercise-induced oxidative stress in chronic obstructive pulmonary disease. Am J Physiol 1999; 277: R1697-R1704.

29. Barnes PJ. Chronic obstructive pulmonary disease. $N$ Engl J Med 2000; 343: 269-280. 